\title{
Population genetics of the invasive ascidian Botryllus schlosseri from South American coasts
}

\author{
Rachel Ben-Shlomo ${ }^{1, *, * *}$, Eitan Reem ${ }^{2,3, * *}$ Jacob Douek $^{3}$, Baruch Rinkevich ${ }^{3}$ \\ ${ }^{1}$ Department of Biology, Faculty of Science and Science Education, University of Haifa - Oranim, Tivon 36006, Israel \\ ${ }^{2}$ Department of Evolutionary and Environmental Biology, Faculty of Science and Science Education, University of Haifa, \\ Haifa 31905, Israel \\ ${ }^{3}$ Israel Oceanography and Limnological Research, National Institute of Oceanography, Tel Shikmona, PO Box 8030, \\ Haifa 31080, Israel
}

\begin{abstract}
The cosmopolitan colonial ascidian Botryllus schlosseri, most likely a Mediterranean Sea and European Atlantic species, is one of the known human-mediated invaders of coastal marine communities. Whereas numerous populations spreading along the Northern Hemisphere coasts have been intensively studied for various population genetics parameters, the data available on the Southern Hemisphere populations is sporadic, based on few and erratic field collections. By using 5 microsatellite loci, we studied gene diversity and possible introduction routes of 4 B. schlosseri populations on the east and west South American coasts. A Hardy-Weinberg exact test for all loci and all populations demonstrated a highly significant heterozygote deficiency. Analyses revealed high gene diversity in the Chilean populations of the west coast, whereas the maximal number of alleles per locus, the highest percentages of natural chimeras and private alleles and the highest levels of variability were observed in the Argentinean population of the east coast. Results further suggest that each of the Chilean populations was founded by a few genotypes. Comparing the genetic identities of South and North American B. schlosseri populations showed extensive dissimilarities, with hardly any common alleles shared, suggesting distinct $B$. schlosseri clades based on molecular biology data.
\end{abstract}

KEY WORDS: Botryllus schlosseri • Gene diversity · Microsatellite · Founder genotype · Anthropogenic invasion

\section{INTRODUCTION}

The colonial ascidian Botryllus schlosseri, most likely a Mediterranean Sea and European Atlantic species (Berrill 1950, Millar 1969, Stoner et al. 2002), is one of the known cosmopolitan invaders of coastal marine communities (Berrill 1950, Ruiz et al. 2000, Ben-Shlomo et al. 2001, 2006, 2008, Rinkevich et al. 2001, Stoner et al. 2002, Paz et al. 2003). In the Northern Hemisphere, this species has invaded all Atlantic coasts as far as northern Scandinavia (B. Rinkevich unpubl. data) and Canada (Carver et al. 2006, LeGresley et al. 2008), and along the northern Pacific coasts it is found in British Columbia, Canada (Epelbaum et al. 2009), and Hokkaido, Japan (Rinkevich \& Saito 1992). Its dispersal is continuously changing, and records of established new populations are constantly being added (B. Rinkevich unpubl. data). In the Southern Hemisphere, this species has been recorded in New Zealand (Ben-Shlomo et al. 2001), Australia and Tasmania (Kott 2005), South Africa (Millar 1955, Simon-Blecher 2003), Chile (Castilla et al. 2005) and Argentina (Orensanz et al. 2002). However, in contrast to the knowledge available on the Northern Hemisphere populations, the data available on the broad distribution of B. schlosseri in the Southern Hemisphere are sporadic, based on few and irregular field collections.

Botryllus schlosseri is an abundant shallow-water sedentary invertebrate, with colonies recorded from the intertidal down to $200 \mathrm{~m}$ depth, above and under stones, on algae and seaweeds and on artificial sub- 
strata (Ben-Shlomo et al. 2001, 2006, 2008, Rinkevich et al. 2001). Larvae are short living ( 1 h). They settle in close proximity to parental colonies $(\sim 1 \mathrm{~m}$; Grosberg 1987, Rinkevich \& Weissman 1987, Ben-Shlomo et al. 2008), which restricts long-range dispersal to those colonies attached to ship hulls, floating objects and hard shells of traveling and hauled marine organisms (Berrill 1950, Lambert \& Lambert 1998, Bernier et al. 2009). This restricted larval dispersal may shape the genetic profiles of distinct populations. Indeed, B. schlosseri populations present micro-geographic genetic structures with localized gene flows (Grosberg 1987, Yund \& O'Neil 2000, Ben-Shlomo et al. 2001, 2006, 2008, Rinkevich et al. 2001, Stoner et al. 2002, Paz et al. 2003). Actually, worldwide distribution and population patterns of $B$. schlosseri are primarily anthropogenic in nature, most likely developed during the last millennium, when European travelers began sailing and exploring the world, co-transferring the European marine biota (Van Name 1945).

While historical records, vectors and the pace of Botryllus schlosseri introductions are mostly unknown, the use of genetic tools may help in elucidating and tracking these events (Ben-Shlomo et al. 2006), detecting sporadic versus recurring invasions and major introduction routes. In the last decade, studies which have concentrated on aspects of population genetics mostly in the Northern Hemisphere (Mediterranean basin, European waters and the east and west coasts of the US), have elucidated high levels of gene diversity and attested repeated invasions (Rinkevich et al. 2001, Stoner et al. 2002, Paz et al. 2003, Ben-Shlomo et al. 2006, 2008). The population structure of $B$. schlosseri has rarely been examined in the Southern Hemisphere, though 1 study (Ben-Shlomo et al. 2001) revealed that New Zealand's populations had probably originated from a few genotypes. By using microsatellite markers, the present study discloses aspects of $B$. schlosseri population genetics on the east and west coasts of South America, analyzing gene diversity and possible introduction routes.

\section{MATERIALS AND METHODS}

Sampling. Botryllus schlosseri were sampled in South America at 4 sites, 3 along the western (Pacific, Chilean) coast (Antofagasta, A1: $24^{\circ} \mathrm{S}$; Algarrobo, A2: $\sim 31^{\circ} \mathrm{S}$; and Puerto Monte Oxena (Puerto Monte, A3: $\sim 41^{\circ} \mathrm{S}$ ) and 1 at the eastern (Atlantic, Argentinian) coast (Mar del Plata, A4: $\sim 38^{\circ} \mathrm{S}$ ) (Fig. 1). All samples were collected from artificial objects and sedentary organisms in shallow waters within marinas, as colonies were not observed growing outside harbors. These collections also present the only sites where $B$. schlosseri populations were found in shallow water

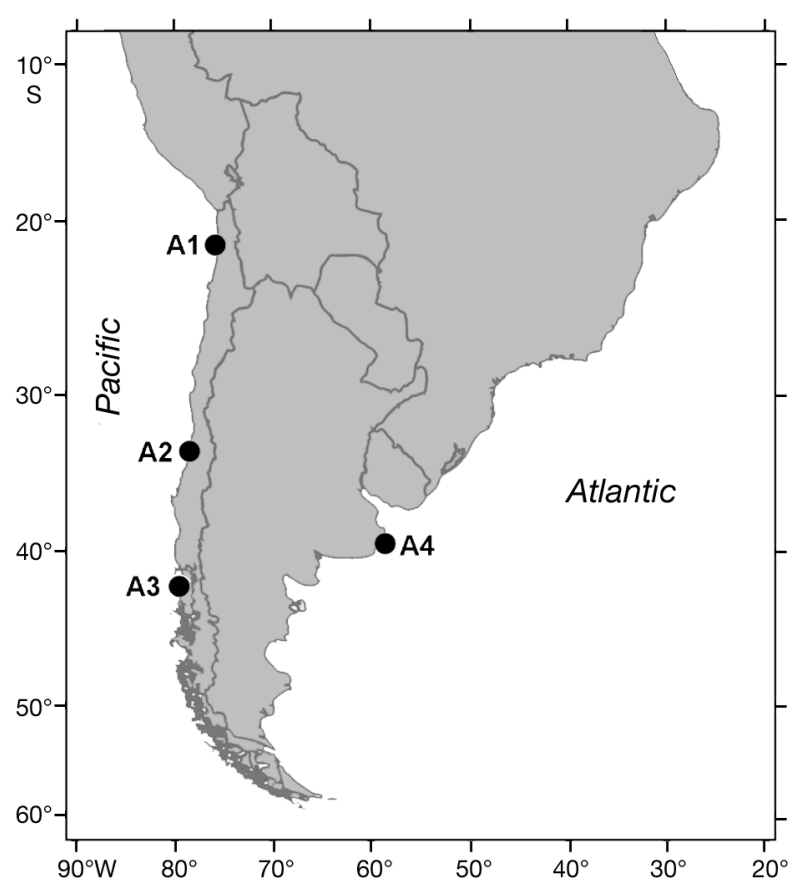

Fig. 1. South America, sampling sites. Chile: A1 = Antofagasta; A2 = Algarrobo; A3 = Puerto Monte Oxena; Argentina: A4 = Mar del Plata

in surveys performed along $>2500 \mathrm{~km}$ (April-July 2008) of each of the South American coasts. The minimal distance between western populations exceeded $800 \mathrm{~km}$. In total, 130 colonies were collected $(30,30,35$ and 35 from Antofagasta, Algarrobo, Puerto Monte Oxena and Mar del Plata). Colonies growing at least $1 \mathrm{~m}$ apart from each other were peeled off the substrate and placed in a container with fresh seawater. We chose colonies that did not show any morphological sign of natural chimerism resulting from fusion of compatible genotypes (e.g. mixed colors of a colony and/or absorption traces).

Genetic analysis. DNA extraction and microsatellite typing of colonies were performed as per Ben-Shlomo et al. (2001). Samples from the field were placed separately into vials containing lysis buffer (Graham 1978), homogenized and extracted with phenol/chloroform. Five Botryllus schlosseri microsatellites, BS-811 (Pancer et al. 1994), PB-29, PB-41, PB-49 and PBC-1 (Stoner et al. 1997), were used following primers and suggested conditions. The F-primer of each microsatellite was labeled with florescent dye (6-Fam, Vic, Ned or Pet) and amplification products were sent to an excampus fluorescence reader (Applied Biosystems). The microsatellite locus that showed the highest number of different alleles (BS-811) was run twice for all samples, labeled with 2 different florescent dyes (Vic or Pet) and sent to 2 alternative fluorescence readers to exclude 
Table 1. Botryllus schlosseri. Allele distribution among South American populations. A1 to A4: sampling sites, see Fig. 1. Bold: most frequent alleles $(>0.3)$. N: sample size (mean number of individuals per loci)

\begin{tabular}{|c|c|c|c|c|c|c|c|c|c|c|c|}
\hline Locus & Allele/N & A1 & A2 & A3 & $\mathrm{A} 4$ & Locus & Allele/N & A1 & A2 & A3 & A4 \\
\hline \multirow[t]{33}{*}{811} & $\mathrm{~N}$ & 26 & 27 & 32 & 34 & \multirow{15}{*}{ PB29 } & 192 & 0.000 & 0.000 & 0.032 & 0.029 \\
\hline & 178 & 0.462 & 0.000 & 0.031 & 0.000 & & 195 & 0.000 & 0.417 & 0.032 & 0.271 \\
\hline & 186 & 0.000 & 0.000 & 0.000 & 0.029 & & 201 & 0.534 & 0.117 & 0.113 & 0.086 \\
\hline & 190 & 0.000 & 0.000 & 0.000 & 0.015 & & 207 & 0.000 & 0.000 & 0.000 & 0.057 \\
\hline & 192 & 0.000 & 0.000 & 0.000 & 0.176 & & 210 & 0.052 & 0.033 & 0.032 & 0.000 \\
\hline & 194 & 0.000 & 0.000 & 0.047 & 0.059 & & 213 & 0.000 & 0.000 & 0.000 & 0.057 \\
\hline & 196 & 0.000 & 0.000 & 0.000 & 0.015 & & 216 & 0.000 & 0.000 & 0.000 & 0.029 \\
\hline & 198 & 0.000 & 0.148 & 0.000 & 0.015 & & 220 & 0.000 & 0.017 & 0.032 & 0.000 \\
\hline & 202 & 0.019 & 0.000 & 0.000 & 0.000 & & 231 & 0.000 & 0.017 & 0.000 & 0.000 \\
\hline & 206 & 0.000 & 0.000 & 0.078 & 0.000 & & $\mathrm{~N}$ & 30 & 30 & 35 & 35 \\
\hline & 208 & 0.115 & 0.000 & 0.281 & 0.000 & & 151 & 0.000 & 0.000 & 0.057 & 0.014 \\
\hline & 210 & 0.000 & 0.000 & 0.000 & 0.015 & & 153 & 0.333 & 0.533 & 0.486 & 0.386 \\
\hline & 212 & 0.000 & 0.111 & 0.109 & 0.206 & & 156 & 0.617 & 0.450 & 0.357 & 0.400 \\
\hline & 214 & 0.000 & 0.704 & 0.344 & 0.000 & & 160 & 0.000 & 0.000 & 0.000 & 0.057 \\
\hline & 216 & 0.115 & 0.000 & 0.000 & 0.118 & & 162 & 0.050 & 0.017 & 0.100 & 0.143 \\
\hline & 220 & 0.038 & 0.000 & 0.000 & 0.000 & \multirow{13}{*}{ PB49 } & $\mathrm{N}$ & 30 & 28 & 32 & 29 \\
\hline & 222 & 0.077 & 0.000 & 0.000 & 0.044 & & 206 & 0.017 & 0.018 & 0.000 & 0.000 \\
\hline & 224 & 0.038 & 0.000 & 0.031 & 0.015 & & $\begin{array}{l}200 \\
207\end{array}$ & $\begin{array}{l}0.01 t \\
0.050\end{array}$ & 0.0100 & 0.313 & 0.052 \\
\hline & 225 & 0.019 & 0.000 & 0.000 & 0.000 & & $\begin{array}{l}20 t \\
209\end{array}$ & 0.033 & 0.000 & 0.000 & 0.000 \\
\hline & 226 & 0.000 & 0.000 & 0.000 & 0.074 & & 217 & 0.000 & 0.000 & 0.000 & 0.190 \\
\hline & 228 & 0.000 & 0.000 & 0.000 & 0.118 & & 219 & 0.200 & 0.232 & 0.031 & 0.103 \\
\hline & 238 & 0.000 & 0.000 & 0.000 & 0.029 & & $\begin{array}{l}219 \\
221\end{array}$ & 0.150 & 0.500 & 0.391 & 0.121 \\
\hline & 240 & 0.000 & 0.000 & 0.000 & 0.029 & & $\begin{array}{l}221 \\
223\end{array}$ & 0.000 & 0.000 & 0.000 & 0.034 \\
\hline & 242 & 0.000 & 0.000 & 0.000 & 0.015 & & 225 & 0.483 & 0.089 & 0.125 & 0.328 \\
\hline & 244 & 0.019 & 0.000 & 0.031 & 0.000 & & 228 & 0.050 & 0.000 & 0.000 & 0.017 \\
\hline & 250 & 0.000 & 0.000 & 0.031 & 0.000 & & 230 & 0.017 & 0.054 & 0.031 & 0.069 \\
\hline & 252 & 0.000 & 0.000 & 0.000 & 0.015 & & 232 & 0.000 & 0.107 & 0.094 & 0.052 \\
\hline & 254 & 0.000 & 0.000 & 0.016 & 0.015 & & 236 & 0.000 & 0.000 & 0.016 & 0.034 \\
\hline & 258 & 0.019 & 0.000 & 0.000 & 0.000 & \multirow[t]{12}{*}{ PB41 } & $\mathrm{N}$ & 29 & 30 & 33 & 35 \\
\hline & 268 & 0.019 & 0.000 & 0.000 & 0.000 & & 165 & 0.000 & 0.000 & 0.000 & 0.086 \\
\hline & 270 & 0.000 & 0.037 & 0.000 & 0.000 & & 167 & 0.086 & 0.250 & 0.091 & 0.143 \\
\hline & 274 & 0.019 & 0.000 & 0.000 & 0.000 & & 169 & 0.431 & 0.350 & 0.348 & 0.186 \\
\hline & 280 & 0.038 & 0.000 & 0.000 & 0.000 & & $\begin{array}{l}109 \\
170\end{array}$ & 0.052 & 0.000 & 0.182 & 0.157 \\
\hline \multirow[t]{7}{*}{$\mathrm{PBC} 1$} & $\mathrm{~N}$ & 29 & 30 & 31 & 35 & & 172 & 0.069 & 0.033 & 0.167 & 0.243 \\
\hline & 143 & 0.034 & 0.000 & 0.097 & 0.000 & & 174 & 0.000 & 0.033 & 0.061 & 0.057 \\
\hline & 172 & 0.000 & 0.000 & 0.000 & 0.029 & & 176 & 0.155 & 0.267 & 0.121 & 0.129 \\
\hline & 179 & 0.000 & 0.250 & 0.081 & 0.186 & & 183 & 0.000 & 0.017 & 0.000 & 0.000 \\
\hline & 183 & 0.190 & 0.000 & 0.371 & 0.114 & & 185 & 0.155 & 0.050 & 0.030 & 0.000 \\
\hline & 186 & 0.069 & 0.150 & 0.129 & 0.029 & & 216 & 0.034 & 0.000 & 0.000 & 0.000 \\
\hline & 189 & 0.121 & 0.000 & 0.081 & 0.114 & & 232 & 0.017 & 0.000 & 0.000 & 0.000 \\
\hline
\end{tabular}

the possibility of errors. All samples showed exactly the same profile with both dyes and readers.

Data analysis. Allele identification, genotyping and observed heterozygosity $\left(H_{0}\right)$, were determined directly from the chromatographs using Genotyper software (Applied Biosystems). Genotyping errors due to null alleles, large allele dropout and scoring of stutter peaks, were tested by Micro-checker software (Van Oosterhout et al. 2004). Expected heterozygosity $\left(H_{\mathrm{e}}\right)$ and Nei's genetic identity $(I)$ were calculated following Nei's gene diversity (Nei 1978). Data were analyzed using Tools for Population Genetic Analyses (TFPGA) version 1.3 (Miller 1997) and GenAlEx version 6.2 (Peakall \& Smouse 2006). The significance level of population differentiation (pairwise analysis of all populations, exact tests; Raymond \& Rousset 1995) was de- termined after 1000 dememorization steps and 10 batches of 2000 permutations per batch, using TFPGA version 1.3 (Miller 1997). The analysis of molecular variance (AMOVA) procedure for testing the partitioning of molecular variance within and among populations and regions followed the methods of Michalakis \& Excoffier (1996) using GenAlEx6.2 (999 permutations; Peakall \& Smouse 2006). Population clustering was performed using the Bayesian partitioning approach (Corrander et al. 2009).

\section{RESULTS}

The 5 microsatellites were highly polymorphic, revealing in total 75 different alleles for the 4 sampled 
populations $(32,15,5,12$ and 11 for loci BS-811, PBC1, PB-29, PB-49 and PB-41, respectively). No large allele dropout was found for any locus. In each locus, a few alleles were abundant (frequency per population $>0.3$, more than $2 \times$ the expected average; Table 1 ). Among these abundant alleles, some were common in all sampled populations and some in 2 to 3 populations only, while others were representative of a specific population. For example, allele 214 of locus 811 was highly represented in the Algarrobo and Puerto Monte populations ( $f=0.344$ and 0.704 , respectively; Table 1 ) and not recorded in the Antofagasta population. The Antofagasta population had a high frequency of allele 178 ( $f=0.462)$, which was present only in Puerto Monte at very low frequency $(f=0.031)$. In contrast, a higher number of alleles, with hardly any predominant one, characterized the Argentinean population of Mar del Plata.

The mean number of different alleles $\left(\mathrm{N}_{\mathrm{a}}\right)$, observed and unbiased expected heterozygosity $\left(H_{\mathrm{o}}\right.$ and $\left.H_{\mathrm{e}}\right)$, fixation index $\left(F_{\mathrm{ST}}\right)$ values, number of frequent $(>5 \%)$ private alleles $\left(\mathrm{N}_{\mathrm{pa}}\right)$ and number of chimeric colonies per population $\left(\mathrm{N}_{\text {Chim }}\right)$ are presented in Table 2 . The Atlantic Coast population of Mar del Plata, Argentina, was the most variable, exhibiting the highest gene diversity $\left(H_{\mathrm{o}}=0.431, H_{\mathrm{e}}=0.823\right)$, an enhanced number of chimeras (29\%) and private alleles (7), and the largest mean number of alleles per locus $\left(\mathrm{N}_{\mathrm{a}}=10.2\right.$; Table 2). The central population in the Pacific Coast (Algarrobo) was marked by the lowest genetic variability values $\left(H_{\mathrm{o}}=0.320, H_{\mathrm{e}}=0.635, \mathrm{~N}_{\mathrm{pa}}=0, N_{\mathrm{a}}=5.4\right)$. Despite that, this population demonstrated the highest percentage of chimeras in the pacific coast $(17 \%$; Table 2). The 4 populations expressed, for all loci, observed heterozygosity that was much lower than expected, resulting in positive and high $F_{\mathrm{ST}}$-values (0.401 to 0.468 ; Table 2 ). A Hardy-Weinberg exact test for all loci and for all populations revealed a highly significant heterozygote deficiency ( $p<0.001)$.

Allele frequencies and distribution differed between the South American populations and allowed differen- tiation among them (Tables $3 \& 4$ ). Genetic distance between populations was relatively high (0.256 to 0.614; Table 3), and differentiation among population pairs across all loci was highly significant (exact test, $\mathrm{p}<0.0001$; Table 3). Bayesian partitioning clustering revealed that each population was clustered separately (Fig. 2): the North American populations were clustered far off the South American populations. AMOVA revealed that $87 \%$ of the calculated variance was within populations and the rest $(13 \%)$ characterized the among-population aspect (Table 4). No difference in variance was found between regions (Pacific versus Atlantic Oceans).

\section{DISCUSSION}

\section{Origin of South American populations}

European explorations during the last millennium have leapt over natural barriers between continents and initiated the introduction of non-indigenous marine species that spread to areas formerly out of their reach (Ruiz et al. 2000, Mooney \& Cleland 2001, Stachowicz et al. 2002). The same applies to the worldwide dispersion of Botryllus schlosseri, including its introduction to the east coast of South America. The first B. schlosseri was recorded in Argentina around 1964 (Amor 1964 cited in Orensanz et al. 2002), more than 130 yr after its arrival on the east coast of North America in the 1830s (Van Name 1945). Documentation of $B$. schlosseri introduction to the west coast of North America is dated as early as 1944 (Cohen \& Carlton 1995), almost simultaneous with that documented for the western coast of South America (1948 in Coquimbo Bay, Chile, $\sim 30^{\circ} \mathrm{S}$; Van Name 1954). Therefore, it may be postulated that populations on the western South American coasts have not originated from the North American west coast or European populations. Consequently, they could originate from introduced East Asian populations, South Pacific popula-

Table 2. Botryllus schlosseri. Genetic diversity of South American populations. N: sample size (mean number of individuals per loci); $\mathrm{N}_{\mathrm{a}}$ : number of different alleles; $H_{\mathrm{o}}$ : observed heterozygosity; $H_{\mathrm{e}}$ : unbiased expected heterozygosity; $F_{\mathrm{ST}}$ : fixation index, $=\left(H_{\mathrm{e}}-H_{\mathrm{o}}\right) / H_{\mathrm{e}}=1-\left(H_{\mathrm{o}} / H_{\mathrm{e}}\right) ; \mathrm{N}_{\mathrm{pa}}$ : number of private alleles (frequency higher than 0.05$) ; \mathrm{N}_{\text {Chim }}$ : number of chimeras (\%)

\begin{tabular}{|c|c|c|c|c|c|c|c|c|c|c|}
\hline \multirow[b]{2}{*}{ Parameter } & \multicolumn{2}{|c|}{ Antofagasta } & \multicolumn{2}{|c|}{ Algarrobo } & \multicolumn{2}{|c|}{ Puerto Monte } & \multicolumn{2}{|c|}{ Mar del Plata } & \multicolumn{2}{|c|}{ Total } \\
\hline & Mean & SE & Mean & SE & Mean & $\mathrm{SE}$ & Mean & $\mathrm{SE}$ & Mean & SE \\
\hline $\mathrm{N}$ & 28.8 & 0.735 & 29 & 0.632 & 32.6 & 0.678 & 33.6 & 1.166 & & \\
\hline $\mathrm{N}_{\mathrm{a}}$ & 7.6 & 1.631 & 5.4 & 0.812 & 7.6 & 1.122 & 10.2 & 2.223 & & \\
\hline$H_{\mathrm{o}}$ & 0.378 & 0.084 & 0.32 & 0.07 & 0.418 & 0.066 & 0.431 & 0.104 & 0.387 & 0.039 \\
\hline$H_{\mathrm{e}}$ & 0.683 & 0.046 & 0.635 & 0.057 & 0.756 & 0.034 & 0.823 & 0.038 & 0.724 & 0.026 \\
\hline$F_{\mathrm{ST}}$ & 0.401 & 0.177 & 0.468 & 0.13 & 0.419 & 0.123 & 0.453 & 0.146 & 0.435 & 0.067 \\
\hline $\mathrm{N}_{\mathrm{pa}}$ & \multicolumn{2}{|c|}{0} & \multicolumn{2}{|c|}{0} & \multicolumn{2}{|c|}{1} & \multicolumn{2}{|c|}{7} & & \\
\hline $\mathrm{N}_{\text {Chim }}$ & \multicolumn{2}{|c|}{$1(3 \%)$} & \multicolumn{2}{|c|}{$5(17 \%)$} & \multicolumn{2}{|c|}{$4(13 \%)$} & \multicolumn{2}{|c|}{$10(29 \%)$} & & \\
\hline
\end{tabular}


Table 3. Genetic distance (Nei 1978) among populations (for all pairs, $\mathrm{p}<0.001)$

\begin{tabular}{|lc|}
\hline Population pair & Genetic distance \\
\hline Antofagasta-Algarrobo & 0.614 \\
Antofagasta-Puerto Monte & 0.398 \\
Antofagasta-Mar del Plata & 0.365 \\
Algarrobo-Puerto Monte & 0.256 \\
Algarrobo-Mar del Plata & 0.397 \\
Puerto Monte-Mar del Plata & 0.338 \\
\hline
\end{tabular}

Table 4. Results of analysis of molecular variance (AMOVA) to test for the partitioning of molecular variance among regions (R) and among and within populations (P) of Botryllus schlosseri $(\mathrm{T}=$ total). Probability, $\mathrm{P}(\mathrm{rand} \geq$ data $)$, for PhiRT, PhiPR and PhiPT is based on permutation across the full data set. $\mathrm{PhiRT}=\mathrm{AR} /(\mathrm{WP}+\mathrm{AP}+\mathrm{AR})=\mathrm{AR} / \mathrm{TOT}$. PhiPT $=$ $(\mathrm{AP}+\mathrm{AR}) /(\mathrm{WP}+\mathrm{AP}+\mathrm{AR})=(\mathrm{AP}+\mathrm{AR}) / \mathrm{TOT}$. AR: estimated variance among regions; AP: estimated variance among populations; WP: estimated variance within populations; TOT: total estimated variance

\begin{tabular}{|lcccc|}
\hline Source & $\mathrm{df}$ & $\mathrm{MS}$ & $\begin{array}{c}\text { Estimated } \\
\text { variance }\end{array}$ & $\%$ \\
\hline Among regions & 1 & 25.386 & 0.000 & $\mathbf{0}$ \\
Among populations & 2 & 33.068 & 0.8690 & $\mathbf{1 3}$ \\
Within populations & 126 & 5.641 & 5.641 & $\mathbf{8 7}$ \\
Total & 129 & & 6.510 & 100 \\
Statistic & Value & P(rand & & \\
& & $\geq$ data) & & \\
\hline PhiRT & -0.031 & 1.000 & & \\
PhiPR & 0.133 & 0.010 & & \\
PhiPT & 0.107 & 0.001 & \\
\hline
\end{tabular}

tions and/or by accompanying edible invertebrates that were trans-shipped for aquaculture across the South American continent (Mugetti et al. 2004, Castilla et al. 2005). However, conclusive data about the actual founding time of the east and the west coasts of South America are not available.

The complete southern population genetics portrait of Botryllus schlosseri is further complicated since the South American populations were marked as genetically closer to the New Zealand populations than to North American populations. It is not clear from the current state of knowledge whether this similarity is coincidental, mirrors an assigned source of donor populations from the Pacific Ocean (New Zealand or Asia) or reflects markers for adaptations to unknown shared Southern Hemisphere conditions. The last 2 explanations may explain the high dissimilarity between North and South American populations. It will be therefore interesting to analyze the worldwide genetic divergent of B. schlosseri populations, based on additional Southern and Northern Hemisphere populations, all revealing major trajectories of population connectivity.

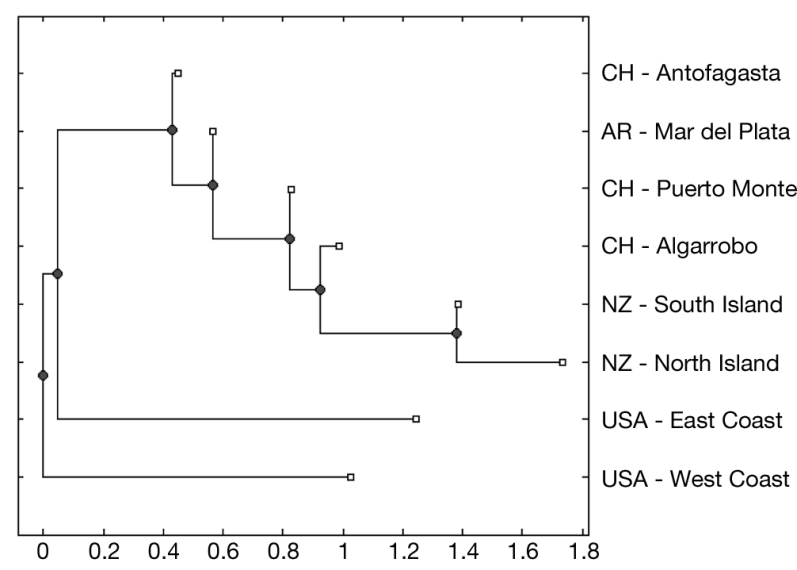

Fig. 2. Bayesian partitioning clustering of Botryllus schlosseri populations from the south and north coasts of America and New Zealand. CH: Chile; AR: Argentina; NZ: New Zealand

\section{Dissimilarity between North and South American populations}

The comparison of the genetic identities between South (present study) and North American Botryllus schlosseri populations (Stoner et al. 2002, Ben-Shlomo et al. 2008) show extensive dissimilarities. In the present study we applied a conservative approach by analyzing only results obtained in the same laboratory, by the same sets of primers and by coalescing alleles of proximate lengths. Consequently, the calculated diversity parameters presented are actually underestimated. Nevertheless, there were hardly any common alleles shared between North and South American populations. The genetic identity values between North and South American populations were mostly lower than 0.2 and the differentiation between them as expressed by $F_{\mathrm{ST}}$ values were around 0.25 (range $=0.2$ to 0.3 ; Table 5). A Bayesian Partitioning approach has clustered the North American populations completely separately from the South American populations.

Both paired $F_{\mathrm{ST}}$ and genetic identity values are included in a range that usually defines distinct species (Hedrick 2000), a suggestion that has no support from classical breeding experiments (Boyd et al. 1990). Based on molecular biology data, genetic structuring of populations of Botryllus schlosseri were shown before (Ben-Shlomo et al. 2001, 2006, Stoner et al. 2002, Lopez-Legentil et al. 2006), hence the results of the present study further suggest distinct $B$. schlosseri clades. However, as the microsatellite allele repertoire of South American B. schlosseri populations are part of the allele panels presented by the Mediterranean and European populations (Rinkevich et al. 2001, Paz et al. 2003, BenShlomo et al. 2006, 2008), we may conclude that all Botryllus schlosseri populations studied today belong to 
a single species. Nonetheless, since North and South American coasts are relatively newly invaded, invasions on the east and west coasts, as on the north and south coasts, may have taken place by founders with a different gamut of microsatellite alleles.

\section{Anthropogenic invasion and genetic variability}

Genetic distances between the 4 studied populations were relatively high, marked with statistically significant differentiations. Nonetheless, $40 \%$ of the alleles were highly frequent in all Chilean populations, in spite of the exceeded $800 \mathrm{~km}$ geographic distance between the closest populations. The 2 southern populations, Puerto Monte and Algarrobo, showed higher genetic identity $(I=0.744)$ and thus were probably first populated by genetically closer genotypes, while the genotypes that founded Antofagasta site were more diverse. Although the Argentinean population was highly variable and presented a higher gene diversity and mean number of alleles, the genetic distance between this population and the 3 Chilean populations is similar to the genetic distances among the Chilean populations.

A common ancestor scenario is not in accordance with presumed historical settlement events. Moreover, since there is no evidence for connectivity between South American east and west coast Botryllus schlosseri populations, gene flow between populations cannot account for the genetic similarity between the Chilean and Argentinean populations. It may be that unnoticed introductions, like those that accompanied oyster transportation between North American coasts (Lambert \& Lambert 1998), could result in the described genetic similarities between the east and the west coast populations in South America. The extensive oyster shipments from the Atlantic coast to the
Pacific coast of North America were documented between 1870 and 1930 (Cohen \& Carlton 1995). Apparently, about 9 to $10 \%$ of introductions of nonindigenous invertebrate species come from aquaculture, primarily oysters (Williams 2007).

\section{Genetic variability and founder genotypes}

Newly established populations are frequently portrayed by the founder's effect, presenting low gene diversity and few major alleles in studied loci (Avise 1994 and references therein). Indeed, our analysis indicates that each of the 3 Chilean populations originated from a few genotypes, presenting common alleles in every locus. The founding genotypes of Puerto Monte likely possessed alleles 214, 183, 153/156, 221 and 169 in loci BS-811, PBC-1 PB-29, PB49 and PB-41, respectively, while the Algarrobo population originated with colonies presenting alleles 214, 195, 153/156, 221 and 169, and the Antofagasta population with alleles 178, 201, 153/156, 225 and 169 in the respective loci. The east coast population of Mar del Plata, Argentina, was more variable, showing a higher mean number of alleles (10.2) than the Chilean populations (6.9), with no clear founder alleles. Our analysis further revealed high gene diversity in all studied South American populations. Nevertheless, the level of variability in the east coast population (Mar del Plata, Argentina, $H_{\mathrm{e}}=$ $0.82)$ was significantly higher than in the west coast populations (Chile, $H_{\mathrm{e}}=0.63$ to $0.76, \mathrm{p}<0.05$ ).

The history of European exploration to the northeast and southeast coasts of America dates back 500 to $600 \mathrm{yr}$, and exploration to New Zealand dates back $150 \mathrm{yr}$. If the major factor affecting genetic variability of a newly established population is the time since the first colonization, it is expected that gene diversity levels would correspond to this time. Consequently, it

Table 5. Pairwise population matrix of Nei's unbiased genetic identity (below diagonal) and pairwise population $F_{\mathrm{ST}}$ values (above diagonal) between Southern Hemisphere and North American populations. NZ: New Zealand

\begin{tabular}{|c|c|c|c|c|c|c|c|c|}
\hline & $\begin{array}{c}\text { Chile - } \\
\text { Antofagasta }\end{array}$ & $\begin{array}{c}\text { Chile - } \\
\text { Algarrobo }\end{array}$ & $\begin{array}{l}\text { Chile - } \\
\text { Puerto } \\
\text { Monte }\end{array}$ & $\begin{array}{c}\text { Argentina - } \\
\text { Mar del } \\
\text { Plata }\end{array}$ & $\begin{array}{l}\text { NZ - } \\
\text { North } \\
\text { Island }\end{array}$ & $\begin{array}{l}\text { NZ - } \\
\text { South } \\
\text { Island }\end{array}$ & $\begin{array}{l}\text { USA - } \\
\text { West } \\
\text { Coast }\end{array}$ & $\begin{array}{l}\text { USA - } \\
\text { East } \\
\text { Coast }\end{array}$ \\
\hline Chile - Antofagasta & & 0.108 & 0.067 & 0.057 & 0.129 & 0.121 & 0.299 & 0.232 \\
\hline Chile - Algarrobo & 0.541 & & 0.056 & 0.069 & 0.099 & 0.138 & 0.317 & 0.257 \\
\hline Chile - Puerto Monte & 0.672 & 0.744 & & 0.043 & 0.073 & 0.107 & 0.264 & 0.226 \\
\hline Argentina - Mar del Plata & 0.694 & 0.672 & 0.713 & & 0.096 & 0.085 & 0.239 & 0.202 \\
\hline NZ - North Island ${ }^{\mathrm{a}}$ & 0.425 & 0.572 & 0.651 & 0.466 & & 0.085 & 0.328 & 0.291 \\
\hline NZ - South Island ${ }^{a}$ & 0.397 & 0.401 & 0.417 & 0.484 & 0.665 & & 0.304 & 0.264 \\
\hline USA - West Coast ${ }^{\mathrm{b}}$ & 0.100 & 0.086 & 0.134 & 0.164 & 0.037 & 0.065 & & 0.366 \\
\hline USA - East Coast ${ }^{\mathrm{b}}$ & 0.226 & 0.164 & 0.133 & 0.173 & 0.004 & 0.047 & 0.062 & \\
\hline
\end{tabular}


is likely that the Atlantic coast populations of America would show higher gene diversity levels, the New Zealand population intermediate levels and the Pacific coast populations of America would show the lowest levels of variability. Surprisingly, the results of our studies (Ben-Shlomo et al. 2001, Stoner et al. 2002, present study) have revealed comparable levels of gene diversity in most of the Botryllus schlosseri invading populations with no correlation with time of introduction or with eco-geographical region. The level of gene diversity $\left(H_{\mathrm{e}}\right)$ in South America Pacific coast populations (0.63 to 0.76 ) was similar to $H_{\mathrm{e}}$ signatures of both North American coasts (0.68 to 0.74) and New Zealand populations ( 0.63 to 0.68 ). The only exception was the population of Mar del Plata, which showed a significantly higher level (0.82). Such a high level is equivalent to the diversity level characterizing the Mediterranean and South European well-established native populations (Paz et al. 2003, Ben-Shlomo et al. 2006).

As differences in diversities between the Argentinean population and the Chilean populations could not be attributed to earlier settlement events on the east coast, one could address the possibility of repeated colonization events in Mar del Plata. Mar del Plata is an important tourist resort and its harbor consists of a nautical sports club, a commercial port and a navy base (Spivak et al. 2006). The La Plata River basin and the adjacent ocean has experienced massive invasion of exotic species that have successfully displaced native species (Mugetti et al. 2004). Invasions could probably be further enhanced by fast degradation of native biodiversity, resulting from overexploited fisheries and marine pollution (Mugetti et al. 2004).

Allogeneic contacts between Botryllus schlosseri colonies may result in colony fusion (chimera formation). Thus the level of chimerism reflects fusion frequencies that are correlated with colony densities a few months prior to the date of collection. We define a colony as a chimera if it shows more than 2 different alleles in a single microsatellite locus. This definition underestimates the actual number of chimeras since it ignores fusions between individuals sharing the same allelic determinants. Chimeric individuals were found in all populations (Table 2). However, the population of Mar del Plata also presents the highest number of natural chimera (29\% of the samples), suggesting higher density of settled colonies in this population.

\section{CONCLUSIONS}

Our genetic analyses, using microsatellite markers, revealed high gene diversity in South American populations of Botryllus schlosseri. A limited number of genotypes probably founded the Pacific Chilean populations, while the Atlantic Argentinean population was repeatedly colonized by new genotypes. The South and North American populations of B. schlosseri showed extensive dissimilarities, suggesting distinct clades.

Acknowledgements. We thank M. Tatian and C. Lagger (Universidad Nacional de Córdoba) for their hospitality and help during the collections in Argentina and D. Reem for help with data analysis. We express our thanks to the anonymous referees, whose helpful suggestions contributed significantly to this study. The work was supported by grants from the EC Marine Genomics Network of Excellence, Israel Science Foundation (550/06) and from the US-Israel Bi-National Foundation (2003-010).

\section{LITERATURE CITED}

Avise JC (1994) Molecular markers, natural history and evolution. Chapman and Hall, New York

Ben-Shlomo R, Douek J, Rinkevich B (2001) Heterozygote deficiency and chimerism in remote populations of a colonial ascidian from New Zealand. Mar Ecol Prog Ser 209: 109-117

Ben-Shlomo R, Paz G, Rinkevich B (2006) Post glacial period and recent invasions shape population genetics of botryllid ascidians along European Atlantic coasts. Ecosystems 9:1118-1127

> Ben-Shlomo R, Motro U, Paz G, Rinkevich B (2008) Pattern of settlement and natural chimerism in the colonial urochordate Botryllus schlosseri. Genetica 132:51-58

Bernier RY, Locke A, Hanson JM (2009) Lobsters and crabs as potential vectors for tunicate dispersal in the southern Gulf of St. Lawrence, Canada. Aquat Invasions 4:105-110

Berrill NJ (1950) The Tunicata. Bernard Quaritch, London

> Boyd HC, Weissman IL, Saito Y (1990) Morphologic and genetic verification that Monterey Botryllus and Woods Hole Botryllus are the same species. Biol Bull 178:239-250

Carver CE, Mallet AL, Vercaemer B (2006) Biological synopsis of the colonial tunicates, Botryllus schlosseri and Botrylloides violaceus. Can Man Rep Fish Aquat Sci 2747 , Fisheries and Oceans Canada, Dartmouth

Castilla JC, Uribe M, Bahamonde N, Clarke M and others (2005) Down under the southeastern Pacific: marine nonindigenous species in Chile. Biol Invasions 7: 213-232

Cohen AN, Carlton JT (1995) Nonidigenous aquatic species in a United States estuary: a case study of the biological invasions of the San Francisco Bay and delta. A report for the US Fish and Wildlife Service and National Sea Grant College Program. National Technical Information Service, Springfield, VA

Corrander J, Marttinen P, Siren J, Tang J (2009) BAPS: Bayesian Analysis of Population Structure version 5.3. Department of mathematics, Abo Akademi University Finland, available at www.abo.fi/mnf/mate/jc/smack_index_ eng.html

Epelbaum A, Herborg LM, Therriault TW, Pearce CM (2009) Temperature and salinity effects on growth, survival, reproduction, and potential distribution of two nonindigenous botryllid ascidians in British Columbia. J Exp Mar Biol Ecol 369:43-52

Graham DE (1978) The isolation of high molecular weight DNA from whole organisms or large tissue masses. Anal Biochem 85:609-613 
Grosberg RK (1987) Limited dispersal and proximity-dependent mating success in the sessile colonial ascidian Botryllus schlosseri. Evolution 41:372-384

Hedrick PW (2000) Genetics of populations, 2nd edn., Jones and Bartlett, Boston, MA

Kott P (2005) Catalogue of Tunicata in Australian waters. Australian Biological Resources Study, Canberra

Lambert CC, Lambert G (1998) Non-indigenous ascidians in southern California harbors and marinas. Mar Biol 130: 675-688

LeGresley MM, Martin JL, McCurdy P, Thorpe B, Chang BD (2008) Non-indigenous tunicate species in the Bay of Fundy, eastern Canada. ICES J Mar Sci 65:770-774

Lopez-Legentil S, Turon X, Planes S (2006) Genetic structure of the star sea squirt, Botryllus schlosseri, introduced in southern European harbours. Mol Ecol 15:3957-3967

Michalakis Y, Excoffier L (1996) A generic estimation of population subdivision using distances between alleles with special reference for microsatellite loci. Genetics 142: 1061-1064

Millar RH (1955) On a collection of ascidians from South Africa. Proc Zool Soc Lond 125:169-221

Millar RH (1969) Ascidies des Eaux Européennes. Catalogue des Principles Salissures Marine, Vol 4. Organisation de Coopération et de Développment Économiques, Paris

Miller MP (1997) Tools for population genetic analyses (TFPGA). Department of Biological Sciences, Northern Arizona University, Flagstaff

Mooney HA, Cleland EE (2001) The evolutionary impact of invasive species. Proc Natl Acad Sci USA 98:5446-5451

Mugetti AC, Calcagno AT, Brieva CA, Giangiobbe MS, Pagani A, Gonzalez S (2004) Aquatic habitat modifications in La Plata River Basin, Patagonia and associated marine areas. Ambio 33:78-87

Nei M (1978) Estimation of average heterozygosity and genetic distance from a small number of individuals. Genetics 89:583-590

Orensanz JM, Schwindt E, Pastorino G, Bortolus A and others (2002) No longer the pristine confines of the world ocean: a survey of exotic marine species in the southwestern Atlantic. Biol Invasions 4:115-143

Pancer Z, Gershon H, Rinkevich B (1994) Direct typing of polymorphic microsatellites in the colonial tunicate Botryllus schlosseri (Ascidiacea). Biochem Biophys Res Commun 203:646-651

Paz G, Douek J, Mo C, Goren M, Rinkevich B (2003) Genetic structure of Botryllus schlosseri (Tunicata) populations from the Mediterranean coast of Israel. Mar Ecol Prog Ser 250:153-162

Peakall R, Smouse PE (2006) GENALEX 6: genetic analysis in

Editorial responsibility: Hans Heinrich Janssen, Oldendorf/Luhe, Germany
Excel. Population genetic software for teaching and research. Mol Ecol Notes 6:288-295

Raymond ML, Rousset F (1995) An exact test for population differentiation. Evolution 49:1280-1283

Rinkevich B, Saito Y (1992) Self-nonself recognition in the colonial protochordate Botryllus schlosseri from Mutsu Bay, Japan. Zoolog Sci 9:983-988

Rinkevich B, Weissman IL (1987) The fate of Botryllus (Ascidiacea) larvae cosettled with parental colonies: beneficial or deleterious consequences? Biol Bull 173:474-488

Rinkevich B, Paz G, Douek J, Ben-Shlomo R (2001) Allorecognition and microsatellite allele polymorphism of Botryllus schlosseri from the Adriatic Sea. In: Sawada H, Yokosawa $\mathrm{H}$, Lambert CC (eds) The biology of ascidians. Springer, Tokyo, p 426-435

$>$ Ruiz GM, Rawlings TK, Dobbs FC, Drake LA, Mullady T, Huqand A, Colwell RR (2000) Global spread of microorganisms by ships. Nature 408:49-50

Simon-Blecher N (2003) Aspects of allorecognition in botryllid ascidians. PhD dissertation, Faculty of Life Sciences, Bar Ilan Univerity, Israel

Spivak ED, Boschi EE, Martorelli SR (2006) Presence of Palaemon macrodactylus Rathbun 1902 (Crustacea: Decapoda: Caridea: Palaemonidae) in Mar del Plata harbor, Argentina: first record from southwestern Atlantic waters. Biol Invasions 8:673-676

Stachowicz JJ, Terwin JR, Whitlatch RB, Osman RW (2002) Linking climate change and biological invasions: ocean warming facilitates nonindigenous species invasions. Proc Natl Acad Sci USA 99:15497-15500

Stoner DS, Quattro JMQ, Weissman IL (1997) Highly polymorphic microsatellite loci in the colonial ascidian Botryllus schlosseri. Mol Mar Biol Biotechnol 6:163-171

Stoner DS, Ben-Shlomo R, Rinkevich B, Weisman IL (2002) Genetic variability of Botryllus schlosseri invasions to the east and west coasts of USA. Mar Ecol Prog Ser 243: 93-100

Van Name WG (1945) The North and South American ascidians. Bull Am Mus Nat Hist 84:220-222

Van Name WG (1954) Ascidians (Ascidiacea). Rep Lund Univ Chile Expedition 14:1-20, Comment: 1948-1949

Van Oosterhout C, Hutchinson WF, Wills DPM, Shipley PF (2004) Micro-Checker: software for identifying and correcting genotyping errors in microsatellite data. Mol Ecol Notes 4:535-538

Williams SL (2007) Introduced species in seagrass ecosystems: status and concerns. J Exp Mar Biol Ecol 350:89-110

> Yund PO, O'Neil PG (2000) Microgeographic genetic differentiation in a colonial ascidian (Botryllus schlosseri) population. Mar Biol 137:583-588

Submitted: October 1, 2009; Accepted: June 2, 2010

Proofs received from author(s): July 29, 2010 